\title{
Percepción de los egresados sanmarquinos respecto de su formación pedagógica en el marco de la educación intercultural
}

\author{
Yoshi Sotomayor Torres \\ Universidad Nacional Mayor de San Marcos, Lima, Perú \\ yoshitasotomayor@gmail.com
}

\begin{abstract}
RESUMEN
El estudio desarrollado tiene como objetivo central analizar las percepciones de los egresados de la Facultad de Educación en la Universidad Nacional Mayor de San Marcos respecto de su formación pedagógica en el marco de la educación intercultural. Entre los objetivos específicos, el estudio indaga en torno a sus percepciones respecto de los contenidos impartidos y las metodologías empleadas por sus docentes, así como sobre sus prácticas preprofesionales y la convivencia estudiantil en un contexto académico y social marcadamente heterogéneo. Se trabajó con un total de 10 informantes que culminaron sus estudios en el 2018. Las entrevistas se desarrollaron entre el 2019 y febrero del 2020 (prepandemia). Entre los principales resultados, se encuentra que tanto la programación curricular como las metodologías empleadas por los docentes no consideran ni incluyen los principios de la pedagogía intercultural. Entre las conclusiones, en la Facultad de Educación de San Marcos rige un currículum de corte monocultural y reproductor del modelo hegemónico, pese a que la característica principal de dicha población estudiantil es su diversidad cultural y lingüística. Esto ocasiona que sus egresados desconozcan estrategias metodológicas para trabajar la diversidad en su desempeño profesional.
\end{abstract}

Palabras Clave: Formación pedagógica, formación docente, educación intercultural, diversidad cultural, interculturalidad crítica, percepción estudiantil

\section{Perception of San Marcos graduates on their pedagogical training within the framework of intercultural education}

\begin{abstract}
The main objective of the study is to analyze the perceptions of the graduates of the Faculty of Education in the National University of San Marcos regarding their pedagogical training in the framework of intercultural education. Among the specific objectives, the study investigates about graduates' perceptions on the contents taught and the methodologies used by their professors, also about their perceptions on their internship and student coexistence in a markedly heterogeneous academic and social context. A total of 10 informants who completed their studies in 2018 were interviewed. The interviews were conducted between 2019 and February 2020 (pre-pandemic). Among the main results, it is found that both the curricular programming and the methodologies used by professors do not consider nor include the principles of intercultural pedagogy. Among the conclusions, in the Faculty of Education of San Marcos rules a monocultural curriculum that reproduces the hegemonic model, even though the main characteristic of the student population is their cultural and linguistic diversity. As a result, its graduates are unaware of methodological strategies for working with diversity in their professional performance.
\end{abstract}

KeYwords: Pedagogical training, teacher training, intercultural education, cultural diversity, critical interculturality, student perception 


\section{Introducción}

En nuestro país, aún no es apreciada ni valorada la diversidad cultural que nos caracteriza. Por el contrario, frente a las diferencias, se sigue manifestando y promoviendo la discriminación, la exclusión y la marginación. Estos fenómenos sociales, que inciden negativamente en una débil democracia como la nuestra, perjudican, y por partida doble, a las poblaciones históricamente postergadas. Así, los últimos datos oficiales confirman que la pobreza y la extrema pobreza, así como los niveles más bajos de escolaridad se presentan en poblaciones en las que la lengua materna es, precisamente, una lengua nativa u originaria. Este es el escenario social y educativo que demanda la puesta en marcha de una propuesta educativa distinta, pensada exclusivamente para superar estas situaciones de desigualdad que, dadas las condiciones actuales pospandemia, se han complejizado y han generado mayor inequidad en cuanto al acceso a educación de calidad.

Si bien la propuesta de Educación Bilingüe Intercultural se remonta a muchas décadas atrás, de acuerdo con Burga (2016), en nuestro país existe como política recién a partir del año 1972; pese a ello, sostiene que, hasta antes del 2012, desde el Estado se hizo muy poco para implementarla como política pública. Pese a los avances al respecto, uno de los mayores escollos que enfrenta esta propuesta educativa es que está pensada exclusivamente para los grupos nativos y comunidades rurales de la Amazonía y la zona andina. Esta situación obedece a que este modelo educativo diferenciado es asumido, más bien, como un vehículo para la homogenización (Peschiera, 2010) antes que como una educación que garantice la libertad, el goce de derechos de todos los peruanos y la equidad. En este punto, es importante destacar que, de acuerdo con el último censo de población y vivienda (2017), la diversidad cultural y lingüística de la población está asentada en las grandes urbes como Lima. De allí la necesidad de diversificar las propuestas de educación intercultural para que se ajusten a las realidades particulares de cada institución educativa. Pero ello no será posible si no se toma en cuenta que hace falta una formación docente que responda a las necesidades reales de la población.

Este es el mayor reto para el MINEDU de acuerdo con el Informe Defensorial 174 (Defensoría del Pueblo, 2016). Respecto de esta problemática, los estudios desarrollados en la última década dan cuenta de la importancia de promover una Educación Intercultural (EI) dirigida a todos los peruanos. Asimismo, autores como Tubino (2012 y 2016), Walsh (2005, 2009 y 2012) inciden en que es necesario superar la interculturalidad funcional, la que reproduce el modelo vigente, y optar por una interculturalidad crítica, capaz de fomentar una verdadera ciudadanía democrática. En tal sentido, en el presente estudio, a partir de un balance respecto del modelo hegemónico capitalista y su influencia o impacto en el campo educativo, se ofrece una visión general respecto de la 
organización del sistema mundo moderno (Wallerstein, 2005), del eurocentrismo y la colonialidad (Quijano, 2014) para, a partir de ello, analizar la propuesta de educación intercultural y algunas estrategias metodológicas enmarcadas en dicho enfoque. En este contexto, la investigación indaga respecto de la formación pedagógica de los egresados de la EAP de Educación de la UNMSM con el fin de analizar su correspondencia con los objetivos educativos planteados por el MINEDU, los cuales, a su vez, están alineados con los objetivos de desarrollo del país.

\section{Métodos y técnicas de investigación}

El enfoque de la investigación es cualitativo, pues el objetivo es indagar en la subjetividad de los participantes del estudio a través de la técnica de la entrevista a profundidad. En tal sentido, siguiendo a Rodríguez (2020), hacemos hincapié en el carácter dialógico de la investigación cualitativa, pues una investigación de este tipo es en esencia un diálogo que se va construyendo día con día. De ahí que la creatividad del investigador cualitativo sea ilimitada, pues "los investigadores cualitativos no somos recolectores de datos", sino personas con capacidad de conceptualizar y teorizar, "y la teoría en lo cualitativo está siempre susceptible de modificaciones, de cambios, porque los referentes empíricos permiten ello, ya que no están contenidos todos en la teoría”. No obstante, la autora señala también que si bien el empleo de matrices, mapas conceptuales, guías de campo u otros elementos, que le permiten al investigador una comprensión muy detallada de las nociones teóricas centrales del estudio, podrían catalogarse como operaciones positivistas, lo cierto es que son necesarias, pues permiten dar una sistematicidad y demostrar un orden que impide desviarse de los objetivos centrales del estudio. Es decir, garantizan la congruencia entre los objetivos, la teoría y el referente empírico. Este aspecto es importante pues si bien, a diferencia del investigador cuantitativo, el cualitativo posee mayor libertad para secuenciar el proceso, coincidimos con la autora en que necesita de estos recursos para vincular la teoría con la práctica y otorgarle versatilidad al proceso.

Por su parte, para Flores (2020) en investigación cualitativa es la persona a cargo del estudio, es decir, el investigador, quien posee la idea de la verdad, de cómo se construye el conocimiento válido. A partir de ello, el investigador cualitativo articula toda su reflexión, porque a diferencia del enfoque positivista (en el que priman las leyes, las verdades y el objeto), en el cualitativo priman las subjetividades. Añade que es la fenomenología la que da la primera entrada para reconocer que pueden existir distintas miradas sobre un mismo fenómeno. De este modo, el investigador cualitativo estará dispuesto a escuchar, a entender y a dialogar. 


\section{Característica de la muestra, instrumentos de recolección de información y procesamiento}

El universo del estudio lo constituyen los alumnos de la Facultad de Educación de la Universidad Nacional Mayor de San Marcos. Para efectos de nuestra investigación, como población de estudio se consideró a los alumnos que, en el 2018, cursaron el último año de estudios. En el siguiente cuadro, se precisa el número total de alumnos que cursó el último año de estudios en la Facultad de Educación por especialidad:

\begin{tabular}{|l|l|}
\hline ESPECIALIDAD & CANTIDAD DE ALUMNOS MATRICULADOS \\
\hline Inicial & 38 \\
\hline Primaria & 46 \\
\hline Matemática y Física & 53 \\
\hline Historia y Geografía & 40 \\
\hline Biología y Química & 18 \\
\hline Inglés y Castellano & 12 \\
\hline Lenguaje, Literatura y Comunicación & 34 \\
\hline Filosofía, Tutoría y Ciencias Sociales & 04 \\
\hline Total & 245 \\
\hline
\end{tabular}

Fuente: Unidad de Estadística e Informática de la Facultad de Educación UNMSM.

De este total, decidimos concentrarnos en estudiantes de una especialidad en particular con el fin de reducir la muestra para garantizar la viabilidad del estudio. Así, del total de egresados de la especialidad de Lenguaje, Literatura y Comunicación (34), se eligió a 08, porque, de acuerdo con la información proporcionada, cumplían con el criterio de haber nacido fuera de Lima: provenían de lugares como Huánuco, Áncash, Huancavelica, La Libertad, Huarochirí.

Adicional a ello, para la selección de la muestra consideramos otro criterio básico: debían ser estudiantes que nacieron en provincia y que, además, cursaron toda su educación básica regular en provincia (fuera de Lima Metropolitana). Esto, debido a que, por el enfoque de nuestro estudio y los objetivos planteados, consideramos fundamental analizar en qué medida la propia identidad cultural de nuestros informantes se relaciona con la visión crítica de estos respecto de su formación pedagógica para un contexto diverso como el peruano. Podemos decir, entonces, que seguimos el denominado "muestreo por criterio lógico", el que se refiere a la selección de todos los casos disponibles que reúnan algún criterio de interés para la investigación” (Tójar, 2006, p. 188).

No obstante, este último dato respecto de la educación básica de los estudiantes seleccionados no lo pudimos corroborar directamente, pues la información propor- 
cionada por la Unidad de Estadística e Informática de la Facultad de Educación de la UNMSM únicamente nos precisaba el lugar de procedencia u origen, mas no información sobre la escolaridad de los estudiantes. Debido a ello, una vez hecho el filtro por el lugar de nacimiento y reducida la muestra, en la etapa de levantamiento de información, esto es, una vez iniciadas las entrevistas a los informantes, se puso en evidencia el hecho de que no todos los seleccionados cumplían con el segundo criterio.

Así, hallamos que solo uno de los estudiantes de la muestra había nacido en provincia y cursado su educación básica regular completa en su lugar de origen (distrito de Chilyia, provincia de Pataz, departamento de La Libertad). Posteriormente, para proseguir sus estudios superiores, migra a Lima y llega a vivir al distrito de Ventanilla. Otro de nuestros informantes, natural de Tambo, en Huancavelica, cursó algunos grados de sus estudios primarios en su pueblo de origen, pero los culminó ya en Lima, en el distrito de San Juan de Lurigancho. En el caso de los demás, lo común fue que, a muy temprana edad, emigraron con sus familias a Lima o bien (uno de ellos) nacieron en Lima (en uno de los casos, los registros de la Facultad no se correspondían con el lugar de nacimiento del estudiante). No fue sencilla esta etapa de la investigación, principalmente debido a cuestiones laborales y de tiempo, así como de dificultades de acceso a información y, adicional a ello, porque se trataba de alumnos que ya habían egresado de la Facultad y que, por lo mismo, se encontraban dispersos y, cada uno de ellos, enfocados en diversas actividades. Este hecho en particular fue una limitante durante el proceso de acopio de información.

Se empleó la entrevista semiestructurada como técnica principal de levantamiento de información. En investigación cualitativa, se denomina entrevista en profundidad al tipo de entrevista más empleada, ya que "se pretende dejar en claro el interés por la obtención de información no superficial, que ahonde en los temas relevantes y que sea persistente en el propósito de interrogar con exhaustividad." (Tójar, 2006, p. 248)

El instrumento validado para este acopio de información fue elaborado en función de las características de nuestros informantes. Una vez superadas las dificultades, pudimos finalmente contar con los testimonios y experiencias valiosas de 06 estudiantes de la especialidad de Lenguaje y Literatura (fue imposible concretar las entrevistas con dos de ellos).

Dadas las dificultades mencionadas, en el proceso, surgió la posibilidad de contar con los testimonios de los estudiantes que en el semestre académico 2018-2 ocuparon los cinco primeros puestos a nivel de toda la base. Esta alternativa, además de dar viabilidad a la investigación, a su vez, la enriqueció, pues pudimos trabajar con dos grupos diferenciados no solo a nivel de su desempeńo académico, sino, también, de su especialidad: los estudiantes que egresaron ocupando los cinco primeros puestos en el año 2018 eran de las especialidades de Primaria e Inglés y Castellano. Estos elementos aportaron significativamente al desarrollo de la investigación, como se verá más ade- 
lante a través de los testimonios de los informantes de ambos grupos. En tal sentido, finalmente, nuestra muestra se compone por dos grupos de estudiantes que, en el año 2018, egresaron de la Facultad de Educación de San Marcos.

\section{Grupo 1:}

Compuesto por seis (6) estudiantes de la especialidad de Lenguaje, Literatura y Comunicación. Los informantes que componen este grupo presentan, como característica común adicional, su procedencia personal o familiar provinciana. En este primer grupo, dicho sea de paso, hay un (1) estudiante bilingüe (quechua / castellano) y más de uno ha crecido en un entorno familiar bilingüe (quechua castellano en todos los casos). Asimismo, en este grupo, encontramos un único caso en el que nuestro/a informante concluyó toda su formación básica escolar fuera de Lima, específicamente en el distrito de Chilyia, provincia de Pataz, departamento de La Libertad. En todos los demás casos, se trata de estudiantes que, o bien apenas nacidos se trasladaron junto con sus familias a Lima o bien nacieron en Lima luego de que sus padres hayan migrado desde sus lugares de origen hacia la capital del país.

\section{Grupo 2:}

Compuesto por cuatro estudiantes que, en el 2018-2, egresaron de la Facultad de Educación ocupando los primeros puestos. Es decir, estamos hablando de los primeros cuadros de profesionales de la Educación egresados de San Marcos. En este grupo, todos nacieron en Lima, todos tienen como lengua materna el castellano y solo uno de ellos manifiesta que sus padres son migrantes (padre ancashino y madre cajamarquina). En todos los demás casos, los padres de nuestros informantes nacieron en Lima. Presentamos, a detalle, información importante respecto de nuestros informantes en el cuadro de doble entrada (ver la siguiente página).

Podemos afirmar que contar con una muestra tan heterogénea (pues no solo estamos hablando de egresados de diversas especialidades, sino también de egresados con diversos niveles de desempeño académico), nos ha mostrado un panorama mucho más complejo en cuanto a sus percepciones en relación a su formación pedagógica en el marco de la educación intercultural. Durante el desarrollo de las entrevistas a profundidad, tal como sostiene Mejía (2002), el proceso de indagación y de acopio de información se adecuó de manera creativa a cada uno de los casos, debido, precisamente, a la heterogeneidad de la muestra del estudio. Así, luego de entrevistar a los informantes del primer grupo, para el acopio de información proveniente del segundo grupo la técnica se modificó levemente en función de sus características particulares.

El segundo grupo está compuesto por los estudiantes que egresaron ocupando los cinco primeros puestos. No obstante, solo pudimos contar con cuatro (4) de ellos para 


\begin{tabular}{|c|c|c|c|c|c|c|c|c|c|c|c|}
\hline \multicolumn{12}{|c|}{ Características de la muestra de estudio } \\
\hline Total & $\begin{array}{c}\text { Características } \\
\text { específicas }\end{array}$ & Informantes & Edad & $\begin{array}{c}\text { Lugar de } \\
\text { nacimiento }\end{array}$ & $\begin{array}{l}\text { Idioma } \\
\text { materno }\end{array}$ & \begin{tabular}{|c|}
$\begin{array}{c}\text { Primaria } \\
\text { (lugar) }\end{array}$ \\
\end{tabular} & \begin{tabular}{|c|}
$\begin{array}{c}\text { Secundaria } \\
\text { (lugar) }\end{array}$ \\
\end{tabular} & Religión & $\begin{array}{c}\text { Año de } \\
\text { estudios FE }\end{array}$ & \begin{tabular}{|c|}
$\begin{array}{c}\text { Procedencia y } \\
\text { LM (papá) }\end{array}$ \\
\end{tabular} & $\begin{array}{c}\text { Procedencia y } \\
\text { LM (mamá) }\end{array}$ \\
\hline \multirow{6}{*}{$\begin{array}{l}\text { Grupo } 1 \\
\text { (Total 6) }\end{array}$} & \multirow{2}{*}{$\begin{array}{c}\text { Especialidad: } \\
\text { Lenguaje, } \\
\text { Literatura y } \\
\text { Comunicación }\end{array}$} & Infor. 1 & 25 & $\begin{array}{c}\text { El } \\
\text { Agustino/Lima }\end{array}$ & castellano & $\begin{array}{c}\text { El } \\
\text { Agustino/Lima }\end{array}$ & $\begin{array}{c}\text { Barrios Altos / } \\
\text { Cercado de } \\
\text { Lima }\end{array}$ & católica & 5 & $\begin{array}{c}\text { San Andrés de } \\
\text { Tupicocha, } \\
\text { Huarochirí/ } \\
\text { castellano }\end{array}$ & $\begin{array}{c}\text { San Andrés de } \\
\text { Tupicocha, } \\
\text { Huarochirí/ } \\
\text { castellano }\end{array}$ \\
\hline & & Infor. 2 & 25 & $\begin{array}{c}\text { Puente Piedra } \\
\text { / Lima }\end{array}$ & castellano & $\begin{array}{c}\text { Puente Piedra } \\
\text { / Lima }\end{array}$ & $\begin{array}{c}\text { Puente Piedra } \\
\text { / Lima }\end{array}$ & católica & 5 & $\begin{array}{l}\text { Cajamarca / } \\
\text { castellano }\end{array}$ & $\begin{array}{l}\text { Ayacucho / } \\
\text { quechua y } \\
\text { castellano }\end{array}$ \\
\hline & \multirow{2}{*}{$\begin{array}{c}\text { Procedencia } \\
\text { personal o } \\
\text { familiar: } \\
\text { provincia }\end{array}$} & Infor. 3 & 30 & $\begin{array}{l}\text { Huacache, } \\
\text { Huari, Áncash }\end{array}$ & castellano & $\begin{array}{c}\text { Los Olivos / } \\
\text { Lima }\end{array}$ & $\begin{array}{l}\text { Los Olivos / } \\
\text { Lima }\end{array}$ & católica & 5 & $\begin{array}{l}\text { Huacache, } \\
\text { Áncash/ } \\
\text { quechua }\end{array}$ & $\begin{array}{l}\text { Huacache, } \\
\text { Áncash / } \\
\text { quechua }\end{array}$ \\
\hline & & Infor. 4 & 25 & $\begin{array}{c}\text { Tambo, } \\
\text { Huancavelica }\end{array}$ & $\begin{array}{l}\text { quechua y } \\
\text { castellano }\end{array}$ & \begin{tabular}{|c|}
$\begin{array}{c}\text { San Juan de } \\
\text { Lurigancho / } \\
\text { Lima }\end{array}$ \\
\end{tabular} & $\begin{array}{c}\text { San Juan de } \\
\text { Lurigancho / } \\
\text { Lima }\end{array}$ & católica & 5 & $\begin{array}{c}\text { Tambo, } \\
\text { Huancavelica / } \\
\text { quechua }\end{array}$ & $\begin{array}{c}\text { Tambo, } \\
\text { Huancavelica / } \\
\text { quechua }\end{array}$ \\
\hline & \multirow{2}{*}{$\begin{array}{c}\text { Diversos niveles } \\
\text { de rendimiento } \\
\text { académico }\end{array}$} & Infor. 5 & 26 & $\begin{array}{c}\text { Chimbote, } \\
\text { Áncash }\end{array}$ & castellano & Lima & Lima & cristiana & 5 & $\begin{array}{l}\text { Chimbote / } \\
\text { castellano }\end{array}$ & \begin{tabular}{|l}
$\begin{array}{l}\text { Chimbote / } \\
\text { castellano }\end{array}$ \\
\end{tabular} \\
\hline & & Infor. 6 & 28 & $\begin{array}{c}\text { Chilyia, Pataz, } \\
\text { La Libertad }\end{array}$ & castellano & $\begin{array}{c}\text { Chilyia, Pataz, } \\
\text { La Libertad }\end{array}$ & $\begin{array}{c}\text { Chilyia, Pataz, } \\
\text { La Libertad }\end{array}$ & $\begin{array}{c}\text { bautizada } \\
\text { católica }\end{array}$ & 5 & $\begin{array}{c}\text { Chilyia, Pataz, } \\
\text { La Libertad / } \\
\text { castellano } \\
\end{array}$ & $\begin{array}{c}\text { Chilyia, Pataz, } \\
\text { La Libertad / } \\
\text { castellano }\end{array}$ \\
\hline \multirow{4}{*}{$\begin{array}{l}\text { Grupo } 2 \\
\text { (Total 4) }\end{array}$} & \multirow{4}{*}{$\begin{array}{l}\text { Especialidad: } \\
\text { Primaria e } \\
\text { Inglés y } \\
\text { Castellano } \\
\text { Procedencia: } \\
\text { Lima } \\
\text { Promedios } \\
\text { ponderados } \\
\text { más altos }\end{array}$} & Infor. 1 & 24 & $\begin{array}{c}\text { La Victoria, } \\
\text { Lima }\end{array}$ & castellano & \begin{tabular}{|c|}
$\begin{array}{c}\text { Cercado de } \\
\text { Lima }\end{array}$ \\
\end{tabular} & $\begin{array}{c}\text { Cercado de } \\
\text { Lima }\end{array}$ & católica & 5 & $\begin{array}{c}\text { Lima / } \\
\text { castellano }\end{array}$ & $\begin{array}{c}\text { Lima / } \\
\text { castellano }\end{array}$ \\
\hline & & Infor. 2 & 28 & $\begin{array}{c}\begin{array}{c}\text { Puente Piedra, } \\
\text { Lima }\end{array} \\
\end{array}$ & castellano & $\begin{array}{c}\begin{array}{c}\text { Puente Piedra, } \\
\text { Lima }\end{array} \\
\end{array}$ & $\begin{array}{c}\text { Puente Piedra, } \\
\text { Lima }\end{array}$ & atea & 5 & $\begin{array}{c}\text { Lima / } \\
\text { castellano }\end{array}$ & $\begin{array}{c}\text { Lima / } \\
\text { castellano }\end{array}$ \\
\hline & & Infor. 3 & 23 & Lima & castellano & \begin{tabular}{|c|}
$\begin{array}{c}\text { Pachacútec, } \\
\text { Ventanilla / } \\
\text { Lima }\end{array}$ \\
\end{tabular} & $\begin{array}{c}\text { Pachacútec, } \\
\text { Ventanilla / } \\
\text { Lima }\end{array}$ & agnóstico & 5 & $\begin{array}{l}\text { Áncahs / } \\
\text { castellano }\end{array}$ & $\begin{array}{l}\text { Cajamarca / } \\
\text { castellano }\end{array}$ \\
\hline & & Infor. 4 & 23 & Lima & castellano & $\begin{array}{c}\text { Ventanilla, } \\
\text { Callao /Lima }\end{array}$ & $\begin{array}{l}\text { Ventanilla, } \\
\text { Callao /Lima }\end{array}$ & deista & 5 & $\begin{array}{l}\text { Lima / } \\
\text { castellano }\end{array}$ & $\begin{array}{l}\text { Lima / } \\
\text { castellano }\end{array}$ \\
\hline
\end{tabular}

las entrevistas: dos de ellos de la especialidad de Inglés y Castellano, y dos de la especialidad de Primaria.

Concluida la etapa de levantamiento de información, el procesamiento de los datos se realizó con el programa Atlas ti, versión 7.5, como soporte informático. Como señala Rodríguez (citadas líneas atrás), este programa informático facilita establecer el diálogo entre las categorías emergentes y la teoría que enmarca un estudio cualitativo.

Las entrevistas fueron grabadas, previo consentimiento de los entrevistados, transcritas e ingresadas a dicho programa para su análisis. La codificación y el análisis de mapa facilitaron la triangulación con el instrumento cuantitativo. Posteriormente, el análisis de los datos obtenidos se organiza en función de cada uno de los objetivos del estudio como a continuación se presenta.

\section{Resultados y discusión}

Los principales hallazgos del estudio desarrollado se organizan en función de los tres objetivos específicos planteados. La siguiente tabla organiza la lógica que sigue la presentación de los resultados y la discusión: 
Objetivo 1: Identificar la percepción de los estudiantes del último ciclo de la Facultad de Educación de la UNMSM respecto de los contenidos y metodologias (curriculo) impartidos durante su formación

Formación pedagógica
en relación con la
interculturalidad
pedagógica para fomentar la educación intercultural

\begin{tabular}{|c|c|}
\hline $\begin{array}{l}\text { Objetivo 2: Identificar la p } \\
\text { UNMSM respecto de }\end{array}$ & $\begin{array}{l}\text { pción de los estudiantes del último ciclo de la Facultad de Educación de la } \\
\text { prácticas preprofesionales en relación con la educación intercultural }\end{array}$ \\
\hline $\begin{array}{l}\text { Prácticas preprofesionales } \\
\text { en relación con la } \\
\text { interculturalidad }\end{array}$ & Prácticas preprofesionales al margen del desarrollo de la interculturalidad \\
\hline
\end{tabular}

Objetivo 3: Conocer la percepción de los estudiantes del último ciclo de la Facultad de Educación de la UNMSM respecto de la diversidad cultural y la convivencia estudiantil en dicho entorno de formación pedagógica

Convivencia estudiantil en Valoración de la diversidad y convivencia armónica un escenario de diversidad Desaprovechamiento de la diversidad \begin{tabular}{l|l}
\cline { 2 - 2 } cultural & Visión crítica de la diversidad cultural
\end{tabular}

\section{Formación pedagógica insuficiente en relación con la interculturalidad}

Los resultados dan cuenta de una formación insuficiente en pedagogía intercultural, pues, de acuerdo con los testimonios de los informantes, la programación curricular en la Facultad es limitada para desarrollar este enfoque educativo. La mayoría de entrevistados considera que no se contemplan cursos diseñados para promover la pedagogía intercultural en ninguna de las especialidades. Señalan que el tema se aborda superficialmente y de acuerdo al criterio de cada docente, mas no hay contenidos programáticos que amplíen la visión del estudiante sobre el tema.

[...] siento que ha habido uno que otro profesor que sí nos ha mencionado sobre los estudiantes que vienen de otras regiones y la importancia de aprender el idioma quechua para poder aprender un poco más, sobre todo si uno va a laborar en otros centros educativos como los de la sierra, pero que hayamos llevado temas dentro de los cursos (sobre interculturalidad), no. (Informante 2, grupo 1)

[...] yo soy egresada de hace un ańo y, pues, ningún profesor ha tocado a fondo ese tema. Si yo sé de ese tema es por las redes, por lo que he leído un poco, pero no por la Facultad. (Informante 6, grupo 1) 
A partir de las entrevistas desarrolladas, se infiere que hay una percepción sesgada sobre la formación intercultural dirigido al nivel primaria. Es decir, la formación intercultural no está transversalizada en la formación pedagógica para todos los niveles de la Educación Básica Regular, tampoco en las diferentes especialidades. Por ejemplo, en la especialidad de Lenguaje, Literatura y Comunicación los entrevistados refieren que se centran en el estudio del castellano.

[...] nosotros, dentro de nuestra Facultad, no hemos manejado ello (el tema consultado). Sé que otras especialidades, por ejemplo, primaria, han tratado lo intercultural, pero nosotros no. Como Lenguaje nos hemos enfocado mucho en lo que es castellano y cuando hemos sido de estudios generales no hemos manejado lo intercultural ni hemos tratado alguna lectura del Ministerio que tenga que ver con ese tema. Yo me he enterado por algunas cosas que he leído, al margen de la Facultad. Por ejemplo, cuando revisas los planes de primaria señalan que se está desarrollando la educación intercultural. (Informante 5, grupo 1)

Los entrevistados del primer grupo remarcan la importancia de la motivación del docente sobre el tema de interculturalidad para que este decida abordarlo o no con los estudiantes. Es decir, cuando un docente tiene práctica o genera investigaciones sobre el tema, trasmite a los estudiantes el interés por la interculturalidad, lo cual supone que no todos lo desarrollan.

Durante el segundo año de la universidad, mientras elegía mi especialidad, una docente de lingüística nos tocó bastante del tema. Más allá de lo que tenía que ver con fonología y lo común del curso, ella se tomó parte del ciclo para hablar sobre la Educación Intercultural Bilingüe (EIB). A través de un trabajo individual, teníamos que averiguar qué materiales hay para fomentar este tipo de educación. Esta fue la única vez en la que nos hablaron a profundidad del tema, ya que la docente viajaba constantemente al interior del país, principalmente a las comunidades indígenas de la selva, para conocer las lenguas de estos lugares. En este curso se realizaba bastante investigación, la docente buscaba que nosotros sepamos del tema y conozcamos otras realidades. (Informante 1 , grupo 1)

Por su parte, los informantes del grupo 2, señalan conocer el enfoque educativo intercultural y bilingüe, debido a los cursos que llevaron como parte de su formación dentro de la Facultad, aunque consideran que dicha preparación ha sido insuficiente sobre todo en cuanto a cómo materializar este enfoque educativo en las aulas. 
Yo llevaba por ejemplo tres Didácticas de las Ciencias Sociales: I, II y III. (...) era la oportunidad para sacar a relucir todo nuestro bagaje cultural. Ahí sí se conectaban con las clases, en cursos como Visión histórica del Perú. Básicamente, en esos cuatro se hablaba de la diversidad de nuestro país. Algunos, por ejemplo, mencionaban que tenían hasta parientes de personajes célebres. Era muy interesante. [...] Ese curso permitía compartir sus experiencias personales. Didáctica de la comunicación II fue otro curso en el que la profesora nos organizaba para exponer [...]. [...] Entonces ahí fue donde aprendimos un poco más. Ahí me di cuenta pues que existen diferentes niveles del manejo del quechua. Porque, por ejemplo, había algunos colegios que estaban clasificados de acuerdo a las lenguas que se hablaban. En unos hablaban quechua y castellano, en otros solo quechua, estos eran los colegios más rurales y otros en los que se hablaba el español, pero donde los estudiantes tenían parientes rurales. Entonces, hay toda una clasificación de los colegios EIB. Ahí fue también otra oportunidad para compartir sobre nuestra cultura y el lenguaje. (Informante 2, especialidad Primaria)

[...] la profesora de Didáctica de la comunicación (...) hacía investigaciones sobre el nivel de comprensión lectora de los niños quechua hablantes. Entonces, sí siento que la universidad me ha formado en este aspecto de comprender y conocer, pero en cuanto a pedagogía no, porque no hay un curso específico sobre educación rural de repente. Eso faltaría. (Informante 2, especialidad Primaria)

Yo creo que en la Facultad no se ha trabajado todavía este tema de la interculturalidad. Yo creo que muchas veces los docentes que asumen esos cursos no tienen mucha experiencia en lo que es EIB. O sea, no están totalmente empoderados sobre el tema. Yo he participado en un taller que lo realizó la Cámara Peruana del Libro, era otra cosa, porque te traían evidencia inclusive de trabajos de alumnos cuya lengua materna era una lengua nativa... se trabajaba en base a proyectos y los chicos tenían que escribir a su alcalde pidiéndoles o hablándole de las necesidades de su colegio... a través de esas cartas es que tu podías ver cuál era su proceso en cuanto a la lecto escritura. Si uno se da cuenta es algo mucho más palpable, mucho más real... y eso yo creo que sí nos falta en la Facultad. (Informante 1, especialidad Inglés y Castellano)

Testimonios como estos evidencian que los contenidos revisados como parte de su malla curricular no han sido suficientes. El siguiente testimonio evidencia, por ejemplo, cómo, a nivel del currículo, aún no se sistematiza contenido específico relacionado con educación intercultural.

[...] siento que sí tocan el tema, pero no les dan la profundidad necesaria. Hablan a grandes rasgos. Te dicen, por ejemplo, esto está en el currículo, esto se está implemen- 
tando, pero no te explican cómo podemos incorporarlo. (Informante 4, especialidad Inglés y Castellano)

En relación con las metodologías aplicadas por los docentes de la Facultad de Educación de San Marcos, estos son algunos de los testimonios recolectados:

[...] hay docentes que solo traen sus diapositivas, las leen y queda ahí. [...] En cuanto a la metodología, hay profesores que manejan la participación de los estudiantes de manera voluntaria y, por otro lado, hay docentes que piden una clase modelo a los alumnos, pero básicamente todo el ciclo era eso y se enfocan en eso descuidando la enseñanza de las diversas metodologías. (Informante 2, grupo 1)

Creo que de un par de profesores me llamó la atención su metodología (sic), pero como la mayoría ya son mayores solo dejaban exposiciones. Por ejemplo, la metodología del profesor "X" sí me gustaba, porque solía preguntar a los estudiantes sobre el tema desarrollado y había una constante participación tanto del alumno como del docente. Los otros profesores solo mandaban exposiciones en grupo y al final comentaban ciertos puntos del tema, mas no promovían el intercambio de opiniones. De los profesores con buena enseñanza, al que más recuerdo es a él. (Informante 3, grupo 1)

En su mayoría, era tradicional, mencionaban a groso modo el tema y no profundizaban aspectos importantes. Siempre era lo mismo. Incluso, algunos temas eran abordados durante diferentes clases, cuando quizá otros temas pudieron ser más destacados que otros. Las clases eran más expositivas, muy pocos docentes buscaban la participación, pero cuando lo hacían (...) no se reforzaba la idea, no se generaba un debate ni otra técnica que exija mayor conocimiento y que permita el aprendizaje colectivo entre pares. Aunque algunos docentes sí buscaban hacer la diferencia. Además, los propios estudiantes exigían hacer diferentes las clases, tanto en los contenidos como en las metodologías, se propuso temas diferentes a los del sílabo y se tenía mayor participación de nosotros - los estudiantes- a través de dinámicas y debates de grupo; esto se desarrolló durante el último año. Algunos docentes mostraban predisposición de hacerlo, pero no lo logran totalmente, quizá porque no están acostumbrados. ¿Estas metodologías trabajaban/fomentaban la práctica de la interculturalidad entre ustedes? En el tema de la interculturalidad, no. (Informante 1, grupo 1)

(A nivel de las metodologías no) ha sido eficiente, porque, como te digo, ellos siguen con lo tradicional. Incluso, había profesores que ni siquiera sabían usar el multimedia. Había otros profesores que iban, se sentaban, decían lean tal página o, si no, ponían sus diapositivas y las pasaban, y leían y leían; eso cualquiera lo puede hacer. (Informante 6, grupo 1) 
En estos testimonios referidos a las metodologías empleadas por los docentes de la FE, prima una desazón en torno a la experiencia estudiantil de nuestros informantes. No obstante, rescatan la iniciativa y el esfuerzo de algunos profesores que sí lograban superar la pedagogía tradicional empleando estrategias que promovían la participación de los estudiantes y el debate. De los testimonios se colige que este esfuerzo, así como la iniciativa docente por desarrollar y promover la investigación es valorada por los estudiantes, pues consideran que es una estrategia que les permite profundizar en el conocimiento de su propia realidad. El balance respecto de este punto, entre los informantes del segundo grupo, es muy similar. Muchos de ellos refieren que había docentes que sí ponían en práctica un aprendizaje activo y promovían la investigación y la contraposición de ideas como estrategias de enseñanza-aprendizaje.

Ahora bien, durante el desarrollo de las entrevistas, nos propusimos consultar a nuestros informantes en torno a las estrategias metodológicas empleadas por los docentes para aprovechar el bagaje cultural diverso de sus estudiantes dentro de la Facultad de Educación. Consultados al respecto, estos fueron sus testimonios:

Creo que el factor enriquecedor provenía cuando era el estudiante quien hacía saber que tenía este bagaje cultural, mas no a la inversa. No era el docente el que generaba ese momento intercultural, ese momento de compartir y de generar distintas ideas o de poder apreciar distintos enfoques. Siempre era del alumno hacia el docente. (Informante 1. Grupo 2, especialidad Inglés y Castellano)

Dependía del docente, porque la mayoría en la Facultad no provienen de provincias, son limeńos. No se percataban mucho si ese alumno era de provincia o no. Básicamente porque si ellos ya estaban estudiando allí, evitaban un poco hablar en su idioma nativo como el quechua. Hablaban español para que los puedan entender. (Informante 4, grupo 2, especialidad Inglés y Castellano)

En el proceso de desarrollo de las entrevistas pudimos corroborar la visión crítica de nuestros informantes en torno a la necesidad de priorizar metodologías que les permitan aprovechar su propio bagaje cultural, es decir, los conocimientos previos que cada uno de ellos posee, el cual incluye, lógicamente, su propia concepción del mundo y la influencia de su cultura familiar y comunitaria. Los recientemente egresados de la Facultad consideran que, muchas de las veces, estos no son tomados en cuenta por los docentes en el proceso de enseñanza aprendizaje. Más bien, muchos de nuestros informantes experimentaron, durante su formación pedagógica en la Facultad de Educación, que los contenidos de los cursos y las propias metodologías de los docentes se tornaban repetitivas y monótonas. Al mismo tiempo, consideran que los cursos en los que aprendieron más fueron aquellos en los que sus docentes planteaban o desarrollaban la 
investigación como elemento central dentro del proceso enseñanza aprendizaje. De esa manera, valoran muchísimo las dinámicas de clase que promueven la lluvia de ideas, la discusión y la contraposición de ideas.

Al respecto, es preciso remarcar que, como puntualiza Asmat (2012) la valoración de los saberes previos de los estudiantes es central en el desarrollo de estrategias y metodologías de enseñanza aprendizaje con enfoque intercultural, toda vez que, más allá de reforzar el vínculo entre docentes y alumnos, ayuda al docente a reconocer la predisposición al aprendizaje en sus estudiantes. Así, el docente deja de ser visto como un simple transmisor de conocimientos para convertirse en un investigador interesado en incluir los conocimientos de los estudiantes y de la comunidad como contenido valioso para la formación pedagógica.

En relación con los conocimientos que manejan los estudiantes que egresan de la FE de San Marcos sobre la interculturalidad y la pedagogía intercultural, los resultados dan cuenta de que, en efecto, son los informantes del grupo 2 quienes evidencian que sus conocimientos sobre educación intercultural son más precisos, lo cual refrenda lo afirmado por los estudiantes del grupo 1 respecto a que no todas las especialidades manejan los mismos contenidos sobre EIB o EI. De esta manera, un aspecto importante relacionado con la formación pedagógica en la Facultad de Educación de San Marcos es que hay especialidades en las que sí, a través del currículo, se está haciendo efectivo, aunque aún de manera incipiente, contenidos relacionados con la educación con enfoque intercultural o bilingüe, sobre todo en especialidades como Primaria. Sin duda, esto obedece a que, de acuerdo a la revisión que se ha efectuado de los planes de estudio, estos varían por especialidad y, en el caso específico del plan de estudios de Primaria, este incluye asignaturas cuyo contenido permite abordar la temática del enfoque intercultural y también bilingüe. Es así que, como se ha ido evidenciando a partir de los testimonios de los entrevistados, en la Facultad se desarrollan contenidos relacionados con la EI, pero solo en algunas especialidades y, muchas veces, a criterio de cada docente. Pese a ello, tanto los entrevistados del grupo 1 como los del grupo 2 coinciden en que los contenidos aún son insuficientes.

Durante las entrevistas a profundidad, nuestros informantes consideraron como un aspecto esencial, pero que no se considera dentro de su formación pedagógica, el manejo de por lo menos una lengua nacional para el ejercicio de su profesión. Al respecto, si bien el quechua aparece mencionado por única vez dentro del plan de estudios (2013) de la especialidad de Lenguaje, Literatura y Comunicación, lo cierto es que se trata de un curso electivo, esto es, de carácter no obligatorio. Los entrevistados consideran que sería importantísimo que su formación pedagógica pudiera contemplar tales contenidos y dotarlos, de esa manera, de mejores herramientas para desempeñarse con éxito en un contexto diverso como el peruano. Al respecto, consideran que desconocer idiomas 
nativos es una limitante para desempeñarse como docentes en zonas rurales donde estos son los usados por la comunidad y por los estudiantes.

[...] pienso que un docente tiene que conocer distintas realidades, no solo Lima, puesto que si decide obtener una plaza en provincia va a conocer otra realidad, quizá se encuentre con un estudiante que tenga dificultades para comunicarse porque la lengua no es la misma, entonces cómo el profesor va a estar preparado para solucionar esta situación. (Informante 4, grupo 1)

Los entrevistados consideran que, durante su formación universitaria, tuvieron limitadas opciones para aprender otros idiomas nativos y de las pocas que había, tampoco las tomaron, por considerarlo innecesario en ese momento. Sin embargo, a partir de su desempeńo profesional, valoran la importancia de estudiar otra lengua, en especial el quechua, por su importancia para el país.

[...] me gustaría aprender el quechua, quizá ahora me doy cuenta, porque — cuando estaba estudiando- había dos cursos que eran opcionales, Impostación de la voz y Quechua. Por las amistades opté por el primero [...] al final no pude optar por conocer quechua a pesar de que el curso se tomó de manera muy básica. Tengo mayor interés por el quechua porque es nuestra segunda lengua y la valoro más. Estoy casi culminando el inglés y siento que desde un principio que, más allá de ser comercial, no tiene tanto valor para mí; me gustaría aprender el quechua porque hay toda una cultura detrás de ella y es nuestra. A veces el inglés se ve forzado en aprender por el hecho de que te permite conocer otros países. (Informante 1, grupo 1)

Uno de estos idiomas necesarios sería el quechua, ya que es uno de los idiomas que más se habla en el interior del país y, de esta manera, me acercaría más a mis estudiantes. (Informante 2, grupo 1)

Yo considero que hubiese sido perfecto que el quechua hubiese sido considerado como curso obligatorio, porque de una u otra forma hubiera aprendido la cultura y costumbres de otras personas [...] me hubiese gustado aprender el quechua, porque es la segunda lengua del Perú, $[\ldots]$ pero también hay otros idiomas, como el asháninca o el shipibo. Me parece que debe ser fundamental, por lo menos en un maestro, que aprenda quechua, porque una persona que quiere dar educación a su país, obviamente, tiene que trabajar en cualquier parte del país, [...]. Esa debería ser la forma de hacer educación, porque no todo el país sabe castellano. (Informante 3, grupo 1) 
Imagínate saber y conocer toda la diversidad que existe en nuestro país pues sería grandioso para mí, yo cuanto quisiera aprender el quechua o saber bailar danzas típicas folclóricas, yo quisiera aprender quechua u otra lengua, pero lamentablemente por ese lado no se ha dado y la Facultad tampoco lo ha promovido [...]. Como te digo, la Facultad sigue con lo tradicional. Cuántos años viene eso de la educación intercultural y la Facultad que es formadora de docentes no se actualiza. Imagínate si San Marcos está así cómo estarán los demás [...]. Tenía un compañero que hablaba quechua y yo cuánto no hubiese querido hablarlo. Si bien es cierto hay un solo curso, pero ese curso es electivo de quechua, entonces si nosotros estamos aspirando a una educación intercultural debemos aprovechar y empezar por la formación del profesor para nosotros tener ese conocimiento y llevar a la práctica. (Informante 1, grupo 1)

Creo que la deficiencia va por ahí. Nosotros hemos recibido clases de inglés dos semestres que también fue básico, como conocimiento general, pero que la mayoría no lo va a aplicar. Y los profesores nos comentaban que antes que enseñen inglés enseñaban Quechua I y Quechua II. Entonces, la deficiencia podría ser esa, que nosotros no podemos acceder a comunicarnos con ellos también. (Informante 3, grupo 2)

Cada uno de los testimonios evidencia el deseo de estos docentes recién egresados por conocer más la cultura nacional. El quechua es bastante valorado por ellos, no obstante, desde la Facultad, no se considera dentro de su currículo oficial. Por el contrario, desde los testimonios de los propios estudiantes, es notorio que la Facultad sigue una lógica eurocentrista, ya que desvaloriza y obvia no solo los conocimientos provenientes de las culturas ancestrales que perviven en nuestro territorio y que, gracias al fenómeno de la migración interna, han transcendido al entorno rural y se hacen visibles en las zonas urbanas, sino que, además, la institución desoye, es decir, se mantiene ciega y cerrada frente a las intenciones y motivaciones intrínsecas de los estudiantes que se reconocen como ciudadanos de un país diverso. Así, queda evidenciado que el conocimiento que se privilegia es el que pertenece a la cultura global, a la cultura que se considera necesaria para el desarrollo profesional del docente peruano.

Es precisamente lo que pretendemos hacer notar, esa visión eurocentrada profundamente anclada no solo a nivel personal sino sobre todo institucional. El modelo hegemónico y la mirada colonial aún permanecen y se hacen evidentes en contenidos curriculares que consideran los conocimientos nativos o de las diferentes culturas ajenas a la cultura dominante como inservibles. En ese nivel se considera al quechua, toda vez que se descarta del contenido a impartir a los futuros docentes porque no se la considera útil o necesaria para su formación. Es aquí donde cabe interrogarse en torno al perfil del egresado: ¿qué visión prima en la formación del docente sanmarquino? ¿no es acaso la 
formación humanística? ¿o es la formación utilitaria que responde a las demandas del mercado global?

Cabe, en este punto, referir lo señalado por Mercado y Consuegra (2018), quienes, en el artículo titulado "Pensamiento sociológico latinoamericano y del Caribe: la superación del eurocentrismo desde una perspectiva intercultural", sostienen la imperiosa necesidad de contrarrestar la colonialidad del saber a partir de una mirada crítica a los postulados eurcéntricos que han "permeado el análisis de los pueblos latinoamericanos y que han contribuido a fortalecer los mecanismos de dominación y exclusión social." (p. 204). A partir de un cuestionamiento claro y preciso respecto de si es posible o no pensar una ciencia social no eurocéntrica, ambas autoras sostienen que no se trata tampoco de un rechazo total hacia la herencia eurocéntrica, sino más bien de la generación de relaciones de complementariedad, pues para comprender nuestra propia realidad latinoamericana las teorías eurocentradas sencillamente no son apropiadas. Estas relaciones de complementariedad, eso sí, deben estar basadas en una propuesta intercultural, pero no cualquier propuesta intercultural, sino exclusiva y claramente la interculturalidad crítica, pues solo esta visión permitirá la construcción de un pensamiento decolonial - no eurocentrado:

[...] es necesario crear lazos que permitan la resignificación de lo que es conocimiento y de quienes son los sujetos habilitados para su producción, con el único fin de reconocer que podemos contribuir a la conformación de otra manera de saber o de pensar más acorde con quienes hemos sido y quiénes somos, reconociendo que desde los sectores académicos, los sectores populares y desde la diversidad étnica y cultural es posible abordar nuestras realidades y atender nuestras necesidades." (p. 206)

\section{Prácticas preprofesionales en relación con la interculturalidad}

De acuerdo con los testimonios obtenidos, las prácticas preprofesionales en la Facultad de Educación de San Marcos inician en el tercer año de estudios, es decir, en el quinto semestre y prosiguen hasta que el estudiante culmine la carrera. Una vez asignada la institución educativa en la que el estudiante desarrollará sus prácticas, estas inician con el análisis de documentos clave dentro de la institución, tales como el Proyecto Educativo Institucional, el Manual de Organización y Funciones, entre otros (quinto semestre). La segunda etapa consiste en la observación de sesiones de aprendizaje y de tutorías (sexto semestre) y la última etapa, en la aplicación y desarrollo de sesiones de aprendizaje (sétimo, octavo, noveno y décimo semestres).

De manera general, los entrevistados consideran que, debido al reducido número de horas semanales que implica el desarrollo de sus prácticas preprofesionales, este no es un espacio que permita conocer a profundidad la realidad de todo cuanto se vive en 
las aulas con los estudiantes. No obstante, consultados acerca de situaciones conflictivas que se hayan presentado durante el desarrollo de las mismas por razones relacionadas con la diversidad étnica o cultural de los estudiantes, los siguientes son algunos de los testimonios que nos brindaron:

No, nunca he presenciado algo así. Lo único que recuerdo es que, cuando iba a observar a mi tutora, había un estudiante que siempre participaba y la tutora lo llamaba por su nombre, pero a los demás los llamaba por sus apellidos. Luego, nos explicó que al alumno no le gustaba su apellido porque sentía vergüenza por ello. (Informante 2, grupo 1)

Sí, siempre se ven, de diferentes maneras, por ejemplo, en los libros, actualmente el Ministerio pone bastantes cosas peruanas, pero a veces los chicos no se sienten identificados con esos chicos que usan polleras o ropas de la selva, quizá porque están muy centralizados en Lima. Lo ideal sería que identifiquen, pero no, ellos lo toman a la burla por el color de piel. A partir de lo que observan en el material, los estudiantes tienden a centrarse en los estereotipos, califican a los costeńos de cierta forma física, a los de la sierra de otra manera y a los de la selva de otra manera. Por ejemplo, dentro del aula he escuchado la frase "cállate serrano". Esto sucede casi siempre, por no decir siempre. (Informante 5, grupo 1)

Actualmente, estoy viviendo en Pachacamac y trabajo como docente en un colegio de Manchay con estudiantes de secundaria de 11 a 16 años, quienes, en su mayoría, son inmigrantes, a diferencia de mi trabajo anterior que se ubicaba en Pueblo Libre y los alumnos eran de Lima y desconocen otro contexto. En cambio, ahora, en el trato con los padres, puedo notar que son de provincia, por el habla, el trato, la preocupación que muestran, su amabilidad, hay aspectos que te permiten darte cuenta que son de provincia, más allá del habla. Dentro de esas experiencias, ¿’has necesitado trabajar, alguna vez, con estrategias didácticas para manejar la diversidad cultural? No, como le comentaba inicialmente, en el caso de la diversidad cultural no mucho, quizá por ahí algunos textos ameritaban hablar del tema, por ejemplo, sobre la lengua quechua o la cultura en otra provincia. Pero no lo abordamos con dinámicas sino solo porque el texto lo requería. (Informante 1, grupo 1)

En el caso del primer testimonio, la entrevistada no recordaba con exactitud el apellido del estudiante en mención. Lo que sí puntualizó es que se trataba de un apellido de origen quechua y que, debido a que se prestaba a los comentarios discriminatorios y burlas de sus compañeros, el estudiante le "suplicó" a la profesora que nunca lo llamara por su apellido. El segundo testimonio da cuenta de la complejidad del tema y de las diversas 
maneras en las que, dentro de las aulas, se manifiestan situaciones de discriminación y de estigmatización por el origen y por las diferencias culturales entre peruanos. En el caso del tercer testimonio, este muestra lo que, a nivel general, nuestros informantes sostienen: si bien durante sus prácticas preprofesionales no pudieron convivir de manera más cercana y continua con los estudiantes, una vez que comenzaron a desempeñarse profesionalmente y a desarrollar ese vínculo más cercano con sus propios alumnos, pudieron notar que la diversidad cultural es mucho más palpable y real de lo que creían. Este testimonio en particular es bastante interesante, pues pese a reconocer la diversidad cultural como un elemento clave en la comunidad educativa en la que se desempeña nuestra informante, su respuesta en cuanto a la necesidad de aplicar estrategias didácticas para abordar tal diversidad es negativa. Esto ocurre debido a que en la formación pedagógica del docente peruano aún se omiten contenidos tan relevantes y absolutamente necesarios como los relacionados con la interculturalidad y la educación intercultural. Aún entre los peruanos y, en este caso particular, entre nuestros informantes, prima la idea errónea de que hablar de interculturalidad y de educación intercultural es hablar de las comunidades y poblaciones andinas y amazónicas únicamente.

Los siguientes testimonios también evidencian cómo situaciones de racismo y discriminación se presentan con recurrencia frente a la mirada pasiva del entorno educativo en su conjunto, pues consultados al respecto, estos fueron los testimonios de nuestros informantes:

En mis prácticas pre profesionales, no, a pesar de que estuve en colegios nacionales. Pero en prácticas profesionales sí. No tanto por el hecho de venir del interior del país, sino por tener o presentar rasgos físicos afrodescendientes. Y era un chico al que lo insultaban de esa manera y pude ver que se llenó de impotencia, de frustración y lo canalizó de manera física. Cuando le pedí salir del aula para conversar con él, pude sentir en su llanto la cólera, no era un llanto de "me ha dolido lo que me ha dicho", sino que era un llanto de "estoy cansado", "estoy harto". Cuando conversé con él, me dijo que no era la primera vez que lo hacían. (Informante 1, especialidad Inglés y Castellano)

Siempre se ve. Los niños son muy crueles. Le decían a un compañerito negro o serrano, o se burlaban de su dejo. Situaciones así. Son niños, y ellos son crueles. Hasta cierto punto son bromas, pero hasta cierto punto. Esto no suele suceder delante de los docentes, así que ellos no prestaban tanta atención. ¿Qué tendría que hacer el docente en aula para prevenir estas situaciones? Es que siempre se trabajaba. No hay una clase específica para trabajar el respeto, sino que siempre se trabaja con el ejemplo durante todos los días, es transversal, pero siempre hay esa parte de los niños que aflora porque ellos son así, son crueles. (Informante 3, especialidad Primaria) 
Un aspecto importante sale a relucir a partir de este testimonio, y es el hecho de que el principio de la interculturalidad, por ser abordada o planteada como un eje transversal dentro del currículo, en la práctica, simple y llanamente se omite, o, peor aún, se piensa que se está desarrollando cuando en realidad se desconoce cómo aplicarla de manera concreta (Tubino, 2016, p. 172). Así, se evidencia lo que Walsh (2005) sostiene precisamente respecto de que, a nivel pedagógico, aún carecemos de un entendimiento certero y compartido de la implicancia de la interculturalidad.

Por otro lado, se pone en evidencia también una normalización de situaciones de ese tipo que, por su gravedad, no deberían tolerarse. Como sostienen diversos autores, entre ellos, de Sousa Santos (2005) y Quijano (2000), a través del tiempo se han configurado nuevas formas de relaciones intersubjetivas de dominación que, camufladas en el discurso de la tolerancia y el mestizaje, normalizan situaciones de injusticia que constituyen atentados contra los derechos y libertades de muchos peruanos.

Como puede verse, entonces, las prácticas preprofesionales, así como la actividad profesional de los docentes egresados de la Facultad de Educación de San Marcos se desarrollan al margen de la interculturalidad y la educación intercultural.

\section{Convivencia estudiantil en un escenario de diversidad cultural}

Como se indicó líneas atrás, el tercer objetivo del estudio busca conocer la percepción de los profesionales egresados de la UNMSM respecto de la diversidad cultural y la convivencia estudiantil en un entorno educativo marcadamente heterogéneo. Al respecto, los hallazgos dan cuenta de una percepción positiva de dicha diversidad, pues de manera general, los entrevistados puntualizan que, precisamente, este es su rasgo identitario. Los testimonios remarcan una convivencia armónica basada en el respeto y la valoración de las diferencias como principios sobre los cuales se asienta su formación como futuros educadores:

Tenemos una convivencia armoniosa, porque nosotros nos respetamos, somos futuros docentes, tenemos que tener los valores muy en claro. Respetar las desigualdades y respetar las diferentes costumbres. (Informante 4, especialidad Primaria)

Nosotros estamos orgullosos de la diversidad y del bagaje cultural que tenemos porque eso nos hace ser quien somos. (Informante 1 especialidad Inglés y Castellano)

Dentro de la Facultad, (la convivencia) es normal. Había respeto y valoración, incluso los de provincia eran más maduros al momento de dar una opinión, se mostraban empeñosos y destacaban en las clases. (Informante 1, grupo 1) 
Yo definiría esta convivencia en un término de igualdad, no ha habido separación por parte de los alumnos (Informante 2, grupo 1)

Asimismo, consideran que dicha diversidad es una característica que los nutre como personas y como profesionales:

Desde que comencé la carrera, en cada sección encuentras gente que viene de diferentes departamentos o de diferentes distritos. Hay diversidad. Algunos de mis compañeros han nacido en provincia. Muchos de ellos hablaban quechua. Esa diversidad desde el comienzo ha sido una experiencia que cambió mi forma de ver el mundo. Muy interesante. La diversidad desde el comienzo fue una experiencia diferente, me cambió muchísimo. En la Facultad de Educación chocamos diferentes mundos, diferentes tradiciones, diferentes costumbres. (Informante 4, especialidad Inglés y Castellano)

La convivencia entre nosotros era muy enriquecedora porque te dan otra visión de distintos tópicos, quieren compartir su perspectiva del mundo y eso hace que se enriquezca mucho más una clase porque no solamente tienes una visión de las cosas que normalmente es la del docente, sino que tienes diferentes perspectivas sobre un mismo tema. (Informante 1, grupo 2)

Incluso, se evidencia que hay una valoración positiva de las características culturales de estudiantes procedentes de provincia. Así, resaltan, por ejemplo, el dominio de una lengua nativa como el quechua.

Tuve una compañera dentro de mi salón, que era de Cusco y siempre se sentía orgullosa de sus antepasados y de lo que le habían heredado. Esta situación era muy bonita, porque ella misma podía explicarnos como era su cultura, incluso recitaba en quechua, esto era bastante apreciable en ella, por rescatar eso, y todos los estudiantes lo apreciaban. (Informante 3, grupo 1)

No obstante, se señala también que es notorio un desaprovechamiento de dicha diversidad como potencial para la formación docente y que aún prima la visión folclórica frente a la mirada crítica que debería primar:

San Marcos es bastante diverso, llegan estudiantes de distintas partes, ya sea de la sierra, la selva o la costa; [...] en Chimbote hay diferente tipo de cultura, diferente a la de la sierra, pero nunca se me presentó la oportunidad de hablar de ello, quizá en un curso o dinámica. Al menos en mi especialidad, esto no sucedió, pero he escuchado que, en otras especialidades, como primaria, sí lo han hecho [...] En el caso de la Facultad, no 
integra mucho la diversidad, porque lo ideal hubiese sido que ellos hagan grupos en donde se pueda entender ello, para que se pueda ver que hay diversidad, de repente hay algunos que son del mismo contexto, de Lima, la sierra o la selva. (Informante 3, grupo 1)

[...] en la Facultad yo he tenido compañeros que han hablado quechua, que provienen de lugares que tiene costumbres muy particulares y, por ejemplo, en las actividades culturales que realiza la Facultad debería incentivar o aprovechar todo ese bagaje cultural, pero lamentablemente todo se centra en una sola línea. O sea, ahí no importa si tú sabes hablar quechua, y si no sabes hablar bien por ti, no se aprovecha, la verdad. (Informante 1, grupo 1)

Se hubiese potenciado si hubiésemos conocido más allá de eso. Quizá si hubiésemos aprendido cómo tratar con estudiantes de provincia como los profesores lo hacen con nosotros porque también ven la situación. Esto de que el docente buscaba fomentar la identidad no se dio, solo fue a groso modo y en situaciones breves, como dinámica o actividad, solo porque lo ameritaba el tema. (Informante 5, grupo 1)

Cuando ingresé... algunos compañeros eran de Lima provincias en mi Facultad. Otros también eran de otros departamentos, por ejemplo, de Piura, pero de bases superiores. En el proceso, ya me he ido dando cuenta de la diversidad cultural, de la presencia de personas quechua hablantes. [...] en primaria sí tratábamos de que esté presente porque, por ejemplo, en las semanas de primaria se trataba de expresar la diversidad del país y se hacían actividades relacionadas con la costa, la sierra, la selva. Hasta ese punto he podido sentir la diversidad cultural. [...] El tema de las danzas es tan cotidiano que ya no me doy cuenta. [...] Yo estudiaba bastante y no me daba espacio para los ensayos o para otras actividades. (Informante del grupo 2, especialidad Primaria)

En San Marcos la forma en que se vive la diversidad es a través de danzas, actividades folclóricas. Yo creo que no es suficiente porque por ejemplo los alumnos podrán expresar su cultura a través de los bailes, pero eso es dentro de la universidad, pero fuera de la universidad se olvidan de todo y viven como una persona común y corriente y no expresan su cultura. Incluso, hay personas que se avergüenzan o tienen miedo de expresar sus costumbres y eso por qué, o sea, porque no se hace nada para que la población tome conciencia de que somos un país diverso y por ende se debe mantener esa diversidad y no dejar de lado como se está perdiendo algunas lenguas. (Informante 1, grupo 1)

Si bien algunos testimonios reflejan aún la visión romántica y folklórica de la diversidad cultural, lo cierto es que prima entre nuestros informantes una mirada más crítica con 
respecto a la misma. Así, si bien son conscientes del gran potencial que, como grupo humano y como Facultad, poseen de cara a su papel como profesionales para un país diverso, consideran que la Facultad los forma con un determinado perfil y para el contexto urbano.

La Facultad o la Universidad en realidad es como un Perú pequeñito porque encuentras todas las realidades, personas que viene de diferentes lugares con diferentes pensamientos y de eso se aprende y te permite ponerte en el lugar de otras personas. En la Facultad de Educación la diversidad cultural se respeta y nos nutre. (Informante 3, especialidad Primaria)

¿Alguna vez has sido testigo de situaciones de discriminación o relego o subvaloración debido a características culturales diferentes entre estudiantes? No, porque nosotros llevamos un curso desde los primeros semestres... se llama pedagogía, y todos los profesores en general nos van marcando el perfil docente. Entonces, nosotros vamos aprendiendo que la educación es un proceso social cultural que mejora a las personas. Desde el primer semestre, ya vas teniendo ese "chip" de la importancia de los valores y de respetar a los demás. Es muy difícil que haya discriminación cultural en la Facultad por el perfil que tiene el ingresante. Porque tenemos una visión más humana. De repente en otras carreras, pero en nuestra Facultad nunca lo he podido percibir.

La diversidad cultural es enriquecedora, porque te permite conocer otro punto de vista, o sea, otra visión. Amplías tu visión. Puedes conocer lenguas, costumbres, valores y creencias diferentes. Sí es importante porque te permite ser más empática y eso es lo que necesitamos en este país. Ponernos en el lugar de la otra persona y entender que somos distintos y con esas distinciones tenemos que aprender a convivir. En lo personal y profesional ha sido enriquecedor, me ha complementado. (Informante del grupo 2, especialidad Primaria)

Yo creo que en la Facultad no, pero que a nivel de la universidad sí (refiriéndose a situaciones de discriminación o subvaloración por cuestiones culturales o lingüísticas), las veces que íbamos a comer juntos al comedor, por ejemplo. Pero en la facultad no.

Los profesionales recientemente egresados de la Facultad de Educación de San Marcos consideran que la forma en que se asume y vive la diversidad cultural dentro la Facultad no es suficiente para desarrollar su carrera docente:

Siempre he participado de las actividades culturales como las danzas, la preparación de platos típicos para explicar las costumbres de diferentes regiones y porque hemos tenido cursos de arte, de danzas y en primaria más aún porque enseñamos todos los 
cursos. De repente no es lo suficiente, porque siempre se puede hacer más. Lo más cercano y palpable a nuestra diversidad son las actividades que realizamos en la Facultad. (Informante 3, grupo 2)

Debería de darse un poco más de importancia, pero tal vez para algunas especialidades no piensan lo mismo. En mi especialidad no ha sido suficiente. A nivel de estrategias no tenemos un curso específico en el que nos hablen de ello. (Informante 4, especialidad Inglés y Castellano)

Yo creo que no, que nos falta mucho, porque muchos de los cursos tienen un enfoque para prepararte para un colegio nacional aquí en Lima, no te preparan para provincia, para ser un docente multigrado, por ejemplo. En el caso de secundaria pasa esto, porque yo soy de secundaria. En el caso de primaria sí. Y cuando tú vas a provincia la realidad es distinta a lo que pasa aquí en Lima. Yo creo que todavía nos falta. La facultad prepara para un contexto urbano. (Informante 1, especialidad Inglés y Castellano)

\section{Conclusiones}

El currículo de la Facultad de Educación es de naturaleza monocultural y eurocéntrica, pues reproduce contenidos provenientes de la llamada cultura hegemónica, la misma que promueve la formación del docente para el sistema mundo moderno. Ello se evidencia no solo en la malla curricular general y específica (de cada especialidad), sino que es refrendado por los mismos estudiantes de la Facultad, quienes tienen conocimientos limitados sobre el enfoque pedagógico intercultural y, más aún, sobre estrategias metodológicas para desarrollar la interculturalidad en su desempeño profesional.

Pese a que son ocho las especialidades en las que se forman a los futuros maestros, se excluyen de manera total las lenguas indígenas o nacionales en las mallas curriculares de cada una de ellas y son, más bien, las lenguas extranjeras, tales como el inglés y el francés, las que se enseñan y promueven en algunas especialidades. Esta constatación evidencia que el docente que egresa de las aulas sanmarquinas no está preparado para desempeńarse acorde a los requerimientos de una sociedad caracterizada por su diversidad étnica, cultural y lingüística.

Las metodologías empleadas por los docentes de la Facultad de Educación aún presentan rezagos de la denominada educación tradicional. Este tipo de enseñanza carece de estrategias que promuevan la contraposición de ideas y el debate. No obstante, de acuerdo con los testimonios de los participantes en el estudio, el debate, la contraposición de ideas, la investigación y los viajes de campo son estrategias que algunos docentes 
emplean y que les ha permitido fortalecer su formación en la medida en que los ha enfrentado con la realidad diversa del país.

La formación pedagógica en la Facultad de Educación de San Marcos prioriza la profesionalización o especialización antes que la formación integral y en ciudadanía intercultural del futuro docente, pues no considera las características históricas ni socioculturales propias de nuestra población.

Las prácticas pre profesionales, si bien son el espacio que enfrenta a los estudiantes de educación con situaciones reales de trabajo, resultan aún insuficientes para que estos identifiquen, prevengan y aborden eficientemente situaciones conflictivas relacionadas con la diversidad étnica, cultural y lingüística que pudieran manifestarse entre estudiantes. Esto ocurre por dos razones centrales: al erróneo entendimiento de lo que implica la transversalización de algunos temas y el número de horas reducido para el desarrollo de las prácticas preprofesionales. Adicional a ello, un factor a considerar es que, en los testimonios de nuestros informantes, se evidencia cierta proclividad a normalizar algunas situaciones de conflicto o discriminación por razones culturales. Esta constatación amerita insistir en la necesidad de incluir contenido relacionado con la interculturalidad y la pedagogía intercultural en la formación de todos los docentes independientemente de su especialidad.

La diversidad se asume con orgullo y como un elemento que enriquece no solo el desarrollo personal, sino también la formación profesional del futuro docente sanmarquino. No obstante, los estudiantes consideran que la Facultad desaprovecha este gran potencial que constituye esta diversidad del estudiantado que bien pudiera potenciar su formación pedagógica de cara a su desempeño en una realidad tan variopinta y heterogénea como lo es la realidad de nuestro país. Este desaprovechamiento de la diversidad cultural y lingüística se evidencia en la visión eurocéntrica del mundo que predomina en la formación docente, pues esta formación apunta netamente al ámbito urbano e hispano. Con ello, se refuerza el centralismo a ultranza que es reflejo de la más profunda desigualdad y exclusión social en desmedro de los que menos tienen y que, en su mayoría, pertenecen o descienden de poblaciones étnicas y culturales nativas.

En la Facultad de Educación prima la visión romántica y folklórica de la diversidad cultural, pues si bien dentro de sus actividades denominadas de extensión o culturales incluye, en su programación anual, el desarrollo de eventos en los que las danzas y diferentes manifestaciones culturales del país se presentan, estas se programan al margen del currículo oficial y no trascienden la concepción tradicional de la diversidad, pues no se discute ni se promueve el pensamiento crítico, la mirada crítica de la diversidad y de la posición que ocupan en el escenario nacional las diversas culturas y pueblos ajenos a Lima. 


\section{Referencias}

Ansión, J. (2012). Universidad e interculturalidad en el Perú. En Universidad e interculturalidad. Desafíos para América Latina (pp. 87 - 102) http://repositorio.pucp.edu.pe/index/handle/123456789/53630

Asmat, T. (2013). Opiniones de los estudiantes del 3ro. de secundaria de Educación Básica Regular del Colegio Mayor Secundario Presidente del Perú sobre las estrategias didácticas que sus profesores aplican para promover una educación intercultural [Tesis de maestría, Pontificia Universidad Católica del Perú]. Repositorio institucional PUCP http://hdl.handle.net/20.500.12404/5015

Burga, E. (2016). La política de Educación Intercultural Bilingüe: avances y retos pendientes. Tarea 91, junio 2016, pp. 16-21 https://tarea.org.pe/wp-content/uploads/2016/08/Tarea91_16_Elena_Burga.pdf

Cépeda, N. (2009). Diversidad cultural de los maestros peruanos: un potencial para una educación intercultural [Tesis de maestría, Pontificia Universidad Católica del Perú]. Repositorio institucional PUCP http://hdl.handle.net/20.500.12404/1164

Defensoría del Pueblo (2016). Educación Intercultural Bilingüe hacia el 2021. Una política de Estado imprescindible para el desarrollo de los pueblos indígenas. Informe Defensorial 174. http://www.justiciaviva.org.pe/new/wp-content/uploads/2016/09/Informe-defensorial174-EIB.pdf

Flores, C. (2020, 22 de mayo). Bases teóricas y epistemológicas de la investigación cualitativa. [Sesión de conferencia]. Ciclo de conferencias del Seminario Internacional Repensando la Metodología Cualitativa, Lima, Perú.

Mejía, J. (2002). Problemas metodológicos de las ciencias sociales en el Perú. Lima: Fondo Editorial de la Facultad de Ciencias Sociales de la Universidad Nacional Mayor de San Marcos

Mercado, K. y Consuegra A. (2018) Pensamiento sociológico latinoamericano y del Caribe: la superación del eurocentrismo desde una perspectiva intercultural. En Revista Pensamiento Actual, vol. 18 núm. 30, junio 2018-noviembre 2018.

doi $10.15517 /$ pa.v18i30.33806

MINEDU (2016). Currículo Nacional de la Educación Básica (2016). Lima: MINEDU http://www.minedu.gob.pe/curriculo/pdf/curriculo-nacional-2016-2.pdf

Peschiera, R. (2010). Un análisis sobre la interpretación de los diferentes actores entorno a la educación intercultural y bilingüe y sus políticas [Tesis de maestría, Pontificia Universidad Católica del Perú]. Repositorio PUCP http://hdl.handle.net/20.500.12404/1370

Quijano, A. (2014). Colonialidad del poder y clasificación social. En cuestiones y horizontes: de la dependencia histórico-estructural a la colonialidad/descolonialidad del poder (pp. 285327). Buenos Aires: CLACSO. Recuperado de http://biblioteca.clacso.edu.ar/clacso/ se/20140507042402/eje3-8.pdf 
Quijano, A. (2000). Colonialidad del poder, eurocentrismo y América Latina. https://www.uv.mx/ jose-marti/files/2018/08/Anibal-Quijano-Colonialidad-del-poder.pdf

Rodríguez, L. (2020, 5 de junio). Aspectos procedimentales en la investigación cualitativa: construcción de instrumentos. [Sesión de conferencia]. Ciclo de conferencias del Seminario Internacional Repensando la Metodología Cualitativa, Lima, Perú.

Sousa Santos, Boaventura de (2011). Introducción. En Las epistemologías del sur. Recuperado de http://www.boaventuradesousasantos.pt/media/INTRODUCCION_BSS.pdf

Tójar, J. (2006). Investigación cualitativa. Comprender y actuar. Editorial La Muralla, Madrid

Mediateca PUCP (2013, 12 de mayo). Los castellanos del Perú. https://www.youtube.com/ watch?v=GsDi5T9Zu_A

Tubino, F. (2012). Formación universitaria para el desarrollo humano abierto a la diversidad. En Universidad e interculturalidad, Desafíos para América Latina. (pp. 107-122) http://repositorio.pucp.edu.pe/index/handle/123456789/53630

Tubino, F. (2016). La interculturalidad en cuestión. Fondo Editorial de la Pontificia Universidad Católica del Perú

Walsh, C. (2005). La interculturalidad en la educación. Ministerio de Educación, Lima

Walsh, C. (2009). Interculturalidad, colonialidad y educación. Revista Educación y Pedagogía, 19(48), 25-35. Recuperado a partir de https://revistas.udea.edu.co/index.php/ revistaeyp/article/view/6652

Walsh, C. (2012). Interculturalidad y (de)colonialidad: perspectivas críticas y políticas. Visão Global, 15 (1-2), 61-74.

Wallerstein, I. (2005). Análisis del sistema-mundo. Una introducción https://sociologiadeldesarrolloi.files.wordpress.com/2014/11/223976110-26842642-immanuel-wallerstein-analisisde-sistemas-mundo.pdf 